University of Nebraska - Lincoln

DigitalCommons@University of Nebraska - Lincoln

Faculty Publications from Nebraska Center for Research on Children, Youth, Families, and Schools
Children, Youth, Families \& Schools, Nebraska Center for Research on

2008

\title{
Teacher-involved conversations with young children during small group activity
}

Tonia Renee Durden

University of Nebraska-Lincoln, tdurden2@unl.edu

Julie Rainer Dangel

Georgia State University, ecejar@langate.gsu.edu

Follow this and additional works at: https://digitalcommons.unl.edu/cyfsfacpub

Part of the Pre-Elementary, Early Childhood, Kindergarten Teacher Education Commons

Durden, Tonia Renee and Rainer Dangel, Julie, "Teacher-involved conversations with young children during small group activity" (2008). Faculty Publications from Nebraska Center for Research on Children, Youth, Families, and Schools. 18.

https://digitalcommons.unl.edu/cyfsfacpub/18

This Article is brought to you for free and open access by the Children, Youth, Families \& Schools, Nebraska Center for Research on at DigitalCommons@University of Nebraska - Lincoln. It has been accepted for inclusion in Faculty Publications from Nebraska Center for Research on Children, Youth, Families, and Schools by an authorized administrator of DigitalCommons@University of Nebraska - Lincoln. 


\title{
Teacher-involved conversations with young children during small group activity
}

\author{
Tonia Durden and Julie Rainer Dangel \\ Department of Early Childhood Education, Georgia State University, Atlanta, GA, USA \\ Corresponding author - T. Durden
}

\begin{abstract}
This qualitative study examines the conversations of two preschool teachers with two- and three-year-old children during small-group activity settings in two highquality child development centers. Using interviews, observations and videotaping of small-group activities, the conversations are characterized in terms of the kind and function of language, the usage of cognitive demands and the reciprocal nature of these conversations. The findings indicate that teachers use declarative statements primarily to manage instruction and encourage language development. While teachers control most conversations, teacher-child reciprocity is evident and more genuine in authentic, teacher-guided activities. In both classrooms, the language during small-group activities is characterized as having low cognitive demands. Teachers and teacher educators need to be more cognizant of their language, including its purpose and opportunities to facilitate cognitively challenging conversations with young children. Recommendations for practice are provided.
\end{abstract}

Keywords: cognitive talk, pre-school, conversational partners

\section{Introduction}

In the context of early childhood education, how teachers talk with children is a critical element in developing their literacy, language and cognitive abilities (Kontos and Wilcox-Herzog 1997; Girolametto and Weitzman 2002; Hayes and Matusov 2005). Research documents the beneficial effects for children of having positive and responsive interactions in multiple activity settings (Kontos 1999). To better understand the nature and role of teacher-involved conversation, this naturalistic study provides an exploration of conversations as two teachers interact with children during small-group activities in a toddler and preschool classroom. For this study, teacher-involved conversation is defined as the "totality of what is said (and not said), how it is said, why it is said" and who says it (Fennimore 2000, 2). Small-group activity is time planned by teachers to meet specific objectives. The small-group activity times in these classrooms differ from free play in that they are planned to meet educational objectives and the teacher directs or guides the activity. Free play is often characterized differently depending on the context; however, in this study, children choose materials such as blocks and puzzles from the shelves and teachers move around the room, interacting as needed.

There are practical and theoretical reasons for this study and it adds to the educational literature and dialogue. On a practical level, there is an emphasis on instruction at earlier and earlier ages. According to Kontos (1999) and Cazden (2001) the amount 
and type of talk with children in the classroom is related to children's learning and development and Johnston suggests that language "creates realities and invites identities" $(2004,9)$. Lindfors (1987) suggests that the school has the greatest potential for contributing to children's communicative competence. Theoretically, Vygotsky identifies the important role of language in learning and suggests that higher mental functioning has its origins in social processes and is mediated by tools and signs such as language (Wertsch and Toma 1995). Vygotskian theory also suggests that adults use language to scaffold the creation and extension of knowledge and teacher talk should be geared to the needs of the child. From a socio-constructivist perspective, experiences (such as joint activity) which promote talk are seen as an important means for conveying meaning and generating new meaning (Rogoff 1993).

The literature also provides convincing arguments for the important role of teacher-child interaction. In their review of the research on teacher-child language Westgate and Hughes $(1997,134)$ find, "There is a pressing need to be able to characterize positive kinds of teacher-involved discourse in a variety of school settings." The work of Cazden (2001), Davies (2005) and Johnston (2004) specifically related to instructional activities and teacher language persuades us to look more closely at teacher-involved conversations during small-group activities.

\section{Literature on teacher-involved conversation}

While many conceptual and practical papers can be found in the literature, we reviewed only research and found 19 studies from the last 25 years (1982-2007), coding each according to its methodology and findings. The majority of studies were quantitative. Qualitative studies often used a priori, structured protocols during observations and audiotaping rather than videotaping. Fourteen of the 19 studied pre-kindergarten or kindergarten classrooms (children aged four to five years old) and the majority occurred during indoor and outdoor playtime. Few studies (four) collected data specific to small-group instructional time and we found little evidence of (a) naturalistic studies during (b) small-group activities with (c) toddler and preschool children (two and three years old). This study was designed to contribute to the existing body of literature by focusing on these three elements.

There were three major constructs identified in the literature that provide a conceptual framework for our thinking: kinds and functions of talk, cognitive demand, and conversational partners. As kinds and function of talk have been thoroughly researched (Tizard et al. 1982; Siegel 1993; Gardner 1996; Kontos 1999; Cazden 2001), we highlight these only as they relate to the two other major constructs.

\section{Kinds and function of talk}

Many studies looked at kinds of talk but only two (Lawton and Fowell 1989; Smith and Dickinson 1994) examined kinds of talk as related to cognitive demand and the development of conversational partnerships between teachers and children. Lawton and Fowell compared the language used by teachers during small-group instruction in two pre-school programs. They found that both groups of teachers used closed questions more frequently than open-ended questions regardless of whether the talk was process or content oriented. They also suggested that providing children with high-level, open-ended questioning extended the opportunities for them to become active conversational partners with teachers and thus more ef- 
ficient communicators. Smith and Dickinson explored the kinds of talk known to foster early literacy development and characterized language as: cognitively challenging talk, pretending talk, didactic talk, and general activity talk. They defined cognitively challenging talk as moving beyond the immediate conversational context to extend students' thinking and responses. These researchers found that the presence of cognitively challenging talk varied depending on the activity level, pedagogical orientation of the teacher and characteristics of the classroom (number of children, length of day). Furthermore, the authors mentioned that teachers were often not cognizant of their use of the different types of talk.

The literature (Gardner 1996; Wilcox-Herzog and Kontos 1998; Kontos 1999) also suggested that the functions (or purposes) of teachers' language ranged from low levels (e.g. as maintaining order) to high levels (e.g. promoting problem-solving). Gardner explored the functions of teachers' language and found that the primary functions were to manage tasks or activities in the classroom and create a positive social context for children. Similar to Wilcox-Herzog and Kontos's research that explored the absence or presence of cognitively challenging talk, Gardner's study found that when preschool teachers used less directive dialogue children became more cognitively and actively engaged in the conversation.

\section{Cognitively challenging talk}

Classic studies suggested that stimulating teacher-child language included engaging children in conversations that required them to develop higher order cognitive skills (Siegel 1982, 1993). According to Siegel, these skills were nurtured and developed as teachers used cognitive demands in their talk. Tizard et al. $(1982,105)$ defined cognitive demands as "verbal requests which adults make of young children and which require them to use particular cognitive skills." Cognitive demands were characterized as open-ended statements and/or questions that provided opportunities for children to examine their previous schematic understandings. According to Davies (2005), high-level questions demand explanation, interpretation, forming opinions and hypotheses. Medium-level questions require labels, descriptions and the use of recall and low-level questioning requests one-word or yes/no responses. Drawing on the cognitively challenging literature, Massey (2004) provided practical examples of how preschool educators can actually facilitate such conversations in their classroom to help develop children's oral language and literacy skills.

\section{Conversational partners}

As teachers encourage children's development it is essential to consider the role of creating spaces for children to initiate conversations and become conversational partners (Wood and Wood 1983). For example, Hayes and Matusov's (2005) examination of teacher talk and student silence revealed both the approaches and challenges teachers faced when attempting to conduct real-life conversations in schools where more rigid teacher talk dominated the discourse. Hayes and Matusov's research was also helpful in that they distinguished and defined monologic and conversational interactions. In monologic interactions the teacher's talk often followed a traditional (I-R-E) pattern of teacher initiating a question, child responding, and teacher's evaluative response/follow up. In contrast, being a conversational partner involved a verbal exchange of genuine inquiries in which the person that asks 
a question does not have a pre-determined answer in mind but rather is interested in learning from the interlocutor's response (Wood and Wood 1983; Hayes and Matusov 2005). Furthermore, Gayle et al. (2006) called our attention to occasions when children spontaneously offered ideas.

We used what we learned from the literature, both methodologically and conceptually, to inform our thinking, data collection and analysis. Despite a robust tradition of research, there are spaces where we can increase our knowledge by focusing on naturalistic examinations of teacher-involved conversation (specifically related to cognitive demand and conversational partnerships) during small-group activities with younger children as the central focus of inquiry.

\section{Methods}

The purpose of this study is to examine teacher-involved conversations during small-group activity times in toddler and preschool classroom. This study addresses the following question:

What are the characteristics of teacher-involved conversations during small-group activities with two- and three-year-old children in high-quality centers?

\section{Context}

We examined conversations in their natural context in a toddler (two-year-old children) and a preschool (three-year-old children) class within two universitysponsored child development centers at a large urban university in a city in the Southeastern United States. In designing this study, we chose high-quality centers for young children. The centers, accredited by the National Association for the Education of Young Children (NAEYC), emphasized children's cognitive and affective development and used learner-centered approaches to learning. Evident in both the classrooms were features of high-quality early childhood settings such as low teacher to child ratios (1:6), large- and small-group experiences, active engagement of children, free choice time, outdoor play, and attention to issues of health and safety. These centers accommodated children of university students, faculty, staff and community members.

The participants in the study included two lead teachers and 30 children (13 in the toddler class and 17 in the preschool class). The lead teachers of each class were purposefully selected from staff at the centers based on their gender, years of experience, style of interacting with children, age of students they taught and accessibility of their classrooms. At the time of the study (pseudonyms used) Mr. Max (white male) had six years of teaching experience and had taught at the current location for two years. Mrs. Mollie (white female) had 16 years of experience and had taught preschoolers for three years at the current location. Both teachers hold college degrees and teacher certification and Mrs. Mollie has a Master's degree in Education. The children range in age from two years to three years old and represent multiple nationalities.

In addition to purposefully selecting the centers and teachers for their high quality, we focused on small-group activity because during this time teacher-involved conversation often becomes apparent and it is a time of explicit interaction between adult and child (Fowell and Lawton 1992). Small-group activity time occurred once each morning. 


\section{Data collection}

The study used qualitative methods including interviews with the teachers, observations in each classroom, videotaped small-group activities and reflections on one video by each teacher. Prior to the study we observed in both classrooms for six weeks to develop rapport and acquaint ourselves with the classroom. At the beginning of the study, we interviewed (audiotaping for accuracy) the two lead teachers to determine their ways of thinking about children and their perceptions of language use in the classroom. Interview questions (available from first author) were developed from the literature review and our professional expertise; they were structured and open-ended. Next, four half-day observations took place in each of the two classrooms (total 14 hours of observation per classroom). The teachers' dialogue was an important focus as well as children's responses; both were recorded in field notes. Our role as researchers was as privileged observers (Wolcott 1988) - people who are known and given easy access to information. To support our observations, we videotaped each teacher working with a small group of children (videotapes range from 24 to 37 minutes), one day per week for four weeks (total of eight taping sessions), using a portable camera with a directional microphone. During the videotaping the teacher typically had specific objectives (e.g. drawing and matching shapes, recognizing colors) and children engaged in unstructured or structured activities centered on the objective. After data collection, we asked the teachers to watch the last videotape and share their thinking about their use of language and confirm that the video was representative of classroom activities and children's behavior. All data collection took place in March and April.

\section{Data analysis}

Data analysis began with reviewing field notes and transcribing verbatim the audio and video tapes to allow for analysis of specific language. The transcripts included the teachers' words and all intelligible utterances of the children and they provided a sequential record of classroom speech during small-group activity. We counted and coded language events (an event is a set of teacher and child comments related to one topic) using the constant comparative method as recommended by Glaser and Strauss $(2006,105)$ and then coded each event into "as many categories of analysis as possible." Often events were assigned multiple codes. Both authors coded the transcripts using a common code list taken from the literature that included the conversational partners (teacher, child or teacher and child), the cognitive demand (high, medium, low as defined earlier) and the inferred function of the language while also searching for new categories. Appendix 1 provides a sample of initial coding for one event. Writing analytic memos informed our continued conversations as we discussed and negotiated the meaning of codes and clarified conflicts. Working as a team was helpful in comparing ideas and cross-checking points, which provided consistency in analysis.

\section{Trustworthiness}

Trustworthiness in qualitative research requires that the findings represent as closely as possible the participants' experiences of the topic being studied. To ensure a trustworthy representation we include detail about the context of our study 
and the varied data-collection strategies employed. Data collection was consistent but not prolonged; this was a limitation in the study. However, we observed the two classrooms and teachers for six weeks prior to data collection to build rapport with the teachers and acquaint ourselves with the classroom. Triangulation of findings provided a convergence of data and allowed us to cross-check our insights and conclusions. We also found that the videotapes provided accurate and detailed representation of the small-group activities. Finally, taking one videotape back to each teacher to review, interpret and confirm the representativeness of the film proved useful. Extending the study to include other teachers is important to consider in future research.

\section{Findings}

Edwards and Mercer (1987) state that classroom talk is dependent on the context and the activity, as well as the talk itself. This section provides a brief introduction to the context describing the teachers and the small-group activities. We then report findings on conversational partnerships with children and use of cognitive demands to stimulate children's thinking. Given page limitations in publications, we chose to report findings primarily from the videotaped activities and interviews with the two teachers; however, we acknowledge that the observations informed our analysis.

\section{Portraits of two teachers}

Mrs. Mollie is an energetic, loquacious person. For her, life is fun and she makes preschool fun. She describes children as curious, spontaneous and full of energy. Actually, those adjectives describe her also. In discussing small-group work during the interview, Mrs. Mollie describes her focus on children's listening skills and cooperation. While she acknowledges that small-group work may have specific objectives depending on the group, she states that she is always incorporating language by "talking about what we are doing and applying previous knowledge and experiences to the current group" (Interview Sp06). In addition, she finds a small-group setting useful in getting to know children and establishing a comfortable environment. She has a daily routine of bringing authentic, or real-life, materials to school to discuss with the children.

Mr. Max's persona and engagement with children in his classroom can be described as quiet, attentive and responsive. In Mr. Max's classroom you see engaged children. When asked about small-group activities, Mr. Max notes, "I'm always incorporating language in those small groups ... by talking about what we are doing and applying previous knowledge to current situations" (Interview Sp06). While focused on language development, Mr. Max acknowledges this is secondary to ensuring that his interactions with students are positive and affirming.

\section{Characteristics of activities}

The activities in both classrooms have common characteristics; they are (a) planned, initiated and directed by the teacher; (b) voluntary (specific children are asked but not required to participate); (c) informal; (d) open-ended (no-predetermined product); and (e) involve specifically selected materials that the children ma- 
nipulate. For example, teachers typically invite three to five children to join in an activity where the materials are prepared; all are seated casually at a table near the sink. The language is informal in nature with the teacher beginning the conversation and children interjecting ideas. Both teachers allow children who are not participating in the small-group activity to interrupt and become part of the conversation. The activities require the children to focus, follow simple directions and make choices about materials. Appendix 2 provides more details about these activities.

\section{Kinds and function of language}

As in many other studies, we analyze data for the kinds and function (or purpose) of language. These are presented briefly as context for more specific analysis. In the three-year-old classroom, approximately three-quarters of the teachers' language events (a set of teacher-child comments related to one topic) take the form of statements. In all four small-group sessions in the two-year-old classroom at least half of the coded events of teachers are a combination of questions and statements.

Seven functions of language emerge from analysis of videotapes (encouraging participation, responding to children, managing the class or instruction, encouraging children's language, conveying ideas, assessment and developing children's thinking). The primary functions of Mrs. Mollie's talk include encouraging participation, managing the class or instruction, encouraging children's language and conveying ideas. The primary function of Mr. Max's language is listening and responding to children and managing the class or instruction. Developing children's thinking is rarely an observed function.

In addition to the quantifiable statements and questions, we also explore qualitative characteristics that exemplify language during small-group activities. There are two qualities that characterize Mr. Max's language during small-group activities: he listens to and repeats students' talk, modeling complete thoughts, and compliments children on their efforts. There are also two primary characteristics of Mrs. Mollie's talk: she thinks aloud and makes connections to children's home and family.

Of the four small-group activities in Mrs. Mollie's classroom two are directed and two are guided, which allows us to make comparisons about conversation in different contexts. Congruent with Gardner's findings (1996), the nature of the activity shows a relationship to the function of the language. The guided activities in Mrs. Mollie's classroom (decorating flower vases and snack making) provide more opportunities to respond to children and require more encouragement of participation, less management of instruction and fewer assessment-type questions. These same activities provide the only examples of explicit language (albeit few) to develop children's thinking. As you might expect, there is evidence of the highest percentage of assessment questions and statements to convey information, and fewer events that included responses to children, in the most didactic of the activities.

\section{Conversational partners}

We analyze data for conversational partnerships (a verbal exchange of genuine inquiry) by looking at events and noting who initiates and who directs the conversation (choosing who speaks and who does not) and the reciprocal and conversational nature of the interaction. We acknowledge that the context of small-group activity provides natural authority to the teacher to direct the discourse. 
In the three-year-old classroom, in all except one activity, the number of teacherinitiated events is higher than the number of child-initiated events. On the contrary, in Mr. Max's class, children initiate the conversations in three out of the four activities, possibly because of his attentive listening. While the children in Mr. Max's class initiate conversations more often it is important to note that these initiations did not show a relationship to children as conversational partners. In other words, while children initiated the conversations in a majority of the events, Mr. Max still focuses and maintains control of the conversational content as seen in the following example:

C: Mr. Max, there's scribbles. A little scribble and a big scribble

T: A little scribble and a big scribble. Good. What color are those scribbles?

C: Um, green

T: Green, Good. (Videotape No. 2, event 1)

An interesting observation seen in this and many other examples is that often children use complete sentences when initiating and one-word answers when responding.

In this study we distinguish between reciprocal conversations (two or more turns on the same subject) and conversational partnerships. Hayes and Matusov (2005) define conversational partnerships as involving a verbal exchange of genuine inquiries, when you do not know the answer ahead of time. Below is an example of Mr. Max and one child as both reciprocal and conversational partners discussing work with a balance scale.

T. How did you make it even like that?

C. I maked it even with one down and one up.

T. Oh I see. How can you make one other side go down?

C. Oh, oh look.

$\mathrm{T}$. Is that one heavier?

C. Yeah...

T. That must have been a heavy bug. Maybe that bug was heavy.

C. That one have two and that one have five.

T. That one's

C. That's mine. (Videotape 4, Event No. 24)

During the activities in both Mr. Max and Mrs. Mollie's classrooms there are many examples of reciprocal exchanges but few examples of children as conversational partners; instead most of the talk with children is monologic in nature. In Mrs. Mollie's class $84 \%$ of the total events are dominated by teacher talk whereas $91 \%$ of the total events are controlled by Mr. Max. Also, we find that in both classrooms there are very few instances in which the children hold conversations with one another during small-group activity. In Mrs. Mollie's classroom, only one child-child conversation transpires and this occurs when Mrs. Mollie leaves the group.

While the teachers controlled the conversations in most instances, reciprocal exchanges and conversational partnerships did occur during specific activities. The frequency is related to the type of activity with strongly didactic and strongly guided or exploratory activities yielding the highest percentage of reciprocal (but very different) conversations. For example, in activity No. 2 (what hatches from eggs), the most didactic or teacher-directed activity, a majority of the events are coded as reciprocal conversations. In this activity the reciprocity is characterized by Mrs. Mollie asking a question and a child answering (i.e. how many eggs are there?). In the more guided or child-centered activity (making a snack together), 
Table 1. Examples of levels of cognitively challenging language during small-group activity.

\begin{tabular}{ll}
\hline Level of language & Example \\
\hline $\begin{array}{l}\text { Low level: } \\
\text { Yes-no question } \\
\text { Label }\end{array}$ & Would you like more paper? \\
Describe & Do you know what this is? \\
Recall & What do these look like to you? \\
Request information & What do these remind you of? \\
High level: & Do you know what they make peanut butter out of? \\
Hypothesize & \\
Compare & What do you think this is? \\
Imagine & What other... \\
Opinion & Guess what happened when... \\
Evaluation & Do you like this? \\
Possibility & What do you like about this? \\
& Could we do this? \\
\hline
\end{tabular}

Table 2. Examples of teacher's language, children's responses and researcher's comments on conversational interactions.

\begin{tabular}{|c|c|c|c|c|}
\hline $\begin{array}{l}\text { Teacher's } \\
\text { comment or } \\
\text { question }\end{array}$ & Commentary & $\begin{array}{l}\text { Child's } \\
\text { response }\end{array}$ & Commentary & Teacher follow-up \\
\hline $\begin{array}{l}\text { What was your } \\
\text { favorite part } \\
\text { about making it? }\end{array}$ & $\begin{array}{l}\text { Asks child to } \\
\text { evaluate and } \\
\text { form opinion }\end{array}$ & $\begin{array}{l}\text { I used } \\
\text { all the } \\
\text { colors }\end{array}$ & $\begin{array}{l}\text { Considers process } \\
\text { and states } \\
\text { opinion }\end{array}$ & $\begin{array}{l}\text { Is that what you liked } \\
\text { about it, (be)cause } \\
\text { you used all the } \\
\text { colors? }\end{array}$ \\
\hline $\begin{array}{l}\text { Where does the } \\
\text { rain come from? }\end{array}$ & $\begin{array}{l}\text { Asks child to } \\
\text { hypothesize/ } \\
\text { speculate/wonder }\end{array}$ & $\begin{array}{l}\text { From the } \\
\text { clouds }\end{array}$ & $\begin{array}{l}\text { Provides an } \\
\text { explanation }\end{array}$ & $\begin{array}{l}\text { The rain came from } \\
\text { the clouds and sky } \\
\text { and went in our } \\
\text { plant and got our } \\
\text { plant really, really } \\
\text { wet. It is so wet, but } \\
\text { we don't want it to } \\
\text { get too wet (be)cause } \\
\text { it will drown the } \\
\text { plant. You can touch } \\
\text { it, you can touch the } \\
\text { dirt. }\end{array}$ \\
\hline $\begin{array}{l}\text { What do these } \\
\text { remind you of? }\end{array}$ & $\begin{array}{l}\text { Asks child to } \\
\text { compare an object } \\
\text { to something else } \\
\text { in his experience; } \\
\text { look for similarities }\end{array}$ & Leaves & $\begin{array}{l}\text { Child provides } \\
\text { an appropriate } \\
\text { one-word } \\
\text { response }\end{array}$ & What else? \\
\hline
\end{tabular}


Table 3. Summary of major constructs: function and kind of language, cognitive demand, conversational partnership and activity.

\begin{tabular}{|c|c|c|c|c|}
\hline \multicolumn{2}{|c|}{ Function and kind of language } & \multirow{2}{*}{$\begin{array}{l}\text { Cognitive } \\
\text { demand } \\
\text { Medium or } \\
\text { high cognitive } \\
\text { demand }\end{array}$} & \multirow{2}{*}{$\begin{array}{l}\begin{array}{l}\text { Conversational } \\
\text { partnership }\end{array} \\
\begin{array}{l}\text { High child } \\
\text { initiation }\end{array}\end{array}$} & \multirow{2}{*}{$\begin{array}{l}\text { Kind of activity } \\
\text { Teacher guided }\end{array}$} \\
\hline $\begin{array}{l}\text { Encourages } \\
\text { participation }\end{array}$ & Statements & & & \\
\hline $\begin{array}{l}\text { Encourages } \\
\text { thinking }\end{array}$ & $\begin{array}{l}\text { Open-ended } \\
\text { questions }\end{array}$ & & $\begin{array}{l}\text { Reciprocal and } \\
\text { genuine } \\
\text { conversations }\end{array}$ & $\begin{array}{l}\text { Authentic/ } \\
\text { purposeful }\end{array}$ \\
\hline $\begin{array}{l}\text { Responds to } \\
\text { children's } \\
\text { needs/interests }\end{array}$ & Listening & & $\begin{array}{l}\text { Teacher directs } \\
\text { conversation }\end{array}$ & $\begin{array}{l}\text { Open-ended/ } \\
\text { exploratory }\end{array}$ \\
\hline $\begin{array}{l}\text { Thinking out } \\
\text { loud }\end{array}$ & & & & $\begin{array}{l}\text { Materials accessible } \\
\text { to children }\end{array}$ \\
\hline \multicolumn{5}{|l|}{$\begin{array}{l}\text { Making } \\
\text { connections }\end{array}$} \\
\hline $\begin{array}{l}\text { Promotes } \\
\text { language }\end{array}$ & Statements & $\begin{array}{l}\text { Low cognitive } \\
\text { demand }\end{array}$ & $\begin{array}{l}\text { High teacher } \\
\text { initiation }\end{array}$ & Teacher directed \\
\hline $\begin{array}{l}\text { Conveys } \\
\text { information }\end{array}$ & $\begin{array}{l}\text { Closed and } \\
\text { yes-no } \\
\text { questions }\end{array}$ & & $\begin{array}{l}\text { Teacher directs } \\
\text { conversation }\end{array}$ & $\begin{array}{l}\text { Theme based } \\
\text { relevance }\end{array}$ \\
\hline $\begin{array}{l}\text { Manages class } \\
\text { and instruction }\end{array}$ & $\begin{array}{l}\text { Requests for } \\
\text { recall and } \\
\text { repetition }\end{array}$ & & $\begin{array}{l}\text { Reciprocal in } \\
\text { I-R-E format }\end{array}$ & $\begin{array}{l}\text { Specific task/ } \\
\text { open-ended } \\
\text { product }\end{array}$ \\
\hline Assesses learning & & & & $\begin{array}{l}\text { Materials accessible } \\
\text { to children }\end{array}$ \\
\hline
\end{tabular}

again a majority of the events include reciprocal conversations. However, in this activity, the reciprocal conversations are more like real-life conversations, that is, Mrs. Mollie asks a question out of genuine interest.

\section{Cognitive demand}

As defined in the literature, cognitive demands include questions and statements that require children to think deeply and offer opportunities to develop higher-order mental processing skills. Low cognitive demands are characterized as those that contain closed questions that require a one-word response and minimal additional information from the students (Siegel 1993; Davis 2005). During the small-group activities in the three-year-old classroom, the cognitive demand of the events is considered predominantly low. Cognitive demand is observed to be moderate to high in only one activity (snack-making), which is also the most authentic and purposeful activity. In this activity, you hear Mrs. Mollie reminding the children of shared experiences, asking them to describe materials, asking their opinion, and asking the children more open-ended questions such as "What are other vegetables that crunch when you eat them?". Table 1 provides additional examples of different levels of language found during the small-group activities. Furthermore, while cognitively challenging talk and conversational partnerships did 
not occur frequently, either separately or together, examples of such conversations along with the researchers' comments can be found in Table 2.

\section{Summary and discussion}

This naturalistic inquiry into teacher-involved conversation helps us better understand the nature of language specifically related to cognitive demand and conversational partnerships and how these are facilitated (or not) during small-group activities. Table 3 summarizes ideas from each of these major constructs and shows how the function and cognitive demand of the teachers' language and the conversational partnership between teacher and child differ depending on the kinds of activity (teacher directed or guided). For example, when the kind of activity is (a) guided rather than directed by the teacher, (b) authentic, and (c) exploratory then the teachers' language changes. In these circumstances, the teacher's language (a) is more open-ended, (b) uses higher cognitive demand, and (c) includes functions such as encouraging thinking, making the nature of the conversation more child-initiated, reciprocal and genuine. According to our findings, Mrs. Mollie and Mr. Max each have unique qualities in their talk. A valuable characteristic of Mrs. Mollie's language is that she thinks aloud and helps children make connections to their home and family. For Mr. Max, language development is an essential goal for his children and to facilitate this goal he uses strategies such as intently listening to children, which allows for child initiation of conversations and thoughtful responses to children. However, the lack of cognitively challenging talk and reciprocal conversations suggests that we need to consider the institutional context of schooling and the nature of small-group activities.

\section{Cognitively challenging talk}

While our findings show teachers' commitment to providing small-group activities and language-rich experiences, there is little evidence of what the literature recommends as cognitively challenging talk. In the literature, such talk is characterized as requiring children to extend beyond one-word responses to the utilization of higher-order mental processing skills (Tizard et al. 1982; Wood and Wood 1983; Hayes and Matusov 2005). In this study we found that there are very few events that contain high cognitive demands. Even in a quality center the dialogue during activities is often monologic and focuses on asking simple questions rather than challenging children's thinking. Furthermore, the Initiate-Respond-Evaluate (I-R-E) pattern traditional in K-12 US schools is also evident in preschool classrooms with children as young as two years old.

\section{Reciprocal conversations}

The literature (Lindfors 1987; Cazden 2001) also addresses the importance of reciprocal conversations in which the teacher and child share the role of leading and directing the conversation. In our study we find that while teachers and children do share in initiating conversations, the teachers control the direction of the majority of conversations with children during small-group activities. Small groups offer an opportunity to converse intimately with children and yet much of the language is limited to managing, instruction and conveying information. 


\section{Role of context}

We acknowledge that by choosing high-quality child development centers and teachers with strong qualifications we hoped to observe authentic, or real-life, meaningful conversations. These conversations were only slightly evident during small-group activity. Research in classrooms indicates that schools as institutions have their own patterns of interaction often characterized by short exchanges directed by the teacher and that conversations are a means for testing knowledge rather than a form of intersubjective activity (Cazden 2001; Hayes and Matusov 2005). These patterns of interaction were evident in both classrooms and child development centers. Our findings are consistent with those of Hayes and Matusov, who suggest there are spaces for authentic conversations in classrooms but "teachers who wish children to learn language by participating in extended meaningful conversation ... must consciously resist institutionally defined teacher talk" (2005, 341). If the norms of institutional discourse foster conventional conversations then teachers need to be very cognizant of the impact of these norms, consciously challenge discourse that is counter-productive to real-life conversations, and create contexts for children to engage in authentic and purposeful conversations. The research from dual-language classrooms (Hayes and Matusov 2005) and family contexts (Dickinson and Tabors 2002) provides examples of promising practices.

\section{Small-group activity}

An important aspect of activities also emerges as we explore the relationship between teacher-involved conversation and the type of activity. We find that there are characteristics of small groups that support naturally occurring dialogues between teachers and children including authentic and open-ended activities, interesting materials prepared and readily accessible to children, and a guided approach by the teacher. We notice that strongly didactic activities require more teacher language to maintain and manage materials and provide direction. Confirming Smith and Dickinson's findings (1994), our research suggests the importance of teachers (a) considering how an activity will either foster or hinder the opportunity for conversation and cognitively challenging talk, and (b) using more cognitively challenging talk during these small-group sessions to foster higher-order thinking. While we focus on small-group activities planned by the teachers for children, it has been suggested that opportunities should also be made for children to initiate activities that center specifically on their interests and inquiries (Girolametto and Weitzman 2002). Our finding are not surprising, based on the literature with older children in prekindergarten, kindergarten and school-aged contexts, yet they are disheartening considering the age of the children (two to three years old) in this study, the high quality of the child development centers and the training of the teachers. Thus we offer recommendations for teachers and teacher educators.

\section{Recommendations}

The research on the importance of conversations with preschool children should inform teacher education and be part of the early childhood teacher education curriculum. While we found multiple articles that provide practical suggestions for teachers (e.g. Woodward et al. 2004), the information for prospective teachers found in 
textbooks proposes only general strategies for teacher-child interactions and provides little assistance in developing conversational skills and instructional practices that will scaffold children's cognitive thinking. As teacher educators, we need to provide teacher candidates with access to research which has specific practical implications and to observe and provide feedback to them on their language use. We should also encourage early childhood teachers and teacher candidates to analyze their own language, perhaps through videotaping or peer observation. This is especially important given the taken-for-granted nature of our words (Johnston 2004). The following suggestions provide a guide for teachers' reflection on their language:

- Consider the function of language as going beyond conveying information and managing instruction to include promoting thinking and encouraging participation. Ask children "how" and "why" questions and solicit their opinions to encourage engagement.

- Use language to challenge children cognitively, e.g. open-ended statements and/or reflective questions that provide children with opportunities to examine their previous schematic understandings. Ask how does it work? And what do you think?

- Make connections to children's experiences, including making family and community a part of the conversation. Use shared vocabulary from previous activities.

- Think about ways to encourage children to become conversational partners, facilitating genuine, reciprocal conversations and encouraging child-initiated inquiries. Ask questions to elicit information of interest.

- Use listening skills, non-verbal prompts and conversational skills to allow opportunities for child-initiated discussions.

- Classify questions and statements according to the level of cognitive demand placed on the learner. Choose high-level questions that require explanation, interpretation and evaluation.

- "Think out loud" modeling metacognitive strategies such as observing and monitoring your thinking and actions.

- Structure and guide activities that facilitate children's language and thinking, such as purposeful and open-ended activities that allow children to use authentic materials in a variety of ways.

Our findings also have implications for policy and future research. From a policy perspective, teacher training for preschool teachers and the teacher-child ratio in classrooms become important issues. In terms of future research, our study is bounded by time and includes a racially homogenous teacher sample; prospective studies should include teachers from diverse cultures and global communities and explore the research questions across multiple school contexts over an extended amount of time. Examining the effects of teacher-involved conversations on children's thinking is a logical next step for us as researchers.

\section{References}

Cazden, C. 2001. Classroom discourse: The language of teaching and learning. Portsmouth, NH: Heinemann. 
Davies, H. 2005. Supporting children's thinking skills. In Perspectives on early childhood education: contemporary research, ed. K. Hirst and C. Nutbrown. Sterling, VA: Trentham.

Dickinson, D., and P. Tabors. 2002. Fostering language and literacy in classrooms and homes. Young Children 57, no. 2: 10-18.

Edwards, D., and N. Mercer. 1987. Common knowledge: The development of understanding in the classroom. London: Methuen.

Fennimore, B. 2000. Talk matters: Refocusing the language of public schooling. New York: Teachers College Press.

Fowell, N., and J. Lawton. 1992. Dependencies between questions and responses during small group instruction in two preschool programs. Early Childhood Research Quarterly 7: 415-439.

Gayle, B., R. Preiss, N. Burrell, and M. Allen. 2006. Classroom communication and instructional processes: Advances through meta-analysis. Mahwah, NJ: Lawrence Erlbaum.

Gardner, R. 1996. How do early childhood teachers support children's learning? Journal for Australian Research in Early Childhood Education 1: 47-56.

Girolametto, L., and E. Weitzman. 2002. Responsiveness of child care providers in interaction with toddlers and preschoolers. Language, Speech, and Hearing Services in Schools 33: 268-281.

Glaser, B., and A. Strauss. 2006. The discovery of grounded theory. New Brunswick, NJ: Aldine Transaction.

Hayes, R., and E. Matusov. 2005. Designing for dialogue in place of teacher talk and student silence. Culture and Psychology 11, no. 3: 339-357.

Johnston, P. 2004. Choice words. Portland, ME: Stenhouse Publishers.

Kontos, S. 1999. Preschool teachers' talk, roles and activities settings during free play. Early Childhood Research Quarterly 14, no. 3: 363-382.

Kontos, S., and A. Wilcox Herzog. 1997. Influences on children's competence in early childhood classrooms. Early Childhood Research Quarterly 12: 247-262.

Lindfors, J. W. 1987. Children's language and learning. Englewood Cliffs, NJ: Prentice-Hall.

Lawton, J., and N. Fowell. 1989. A description of teacher and child language in two preschool programs. Early Childhood Research Quarterly 4: 407-432.

Massey, S. 2004. Teacher-child conversation in the preschool classroom. Early Childhood Education Journal 31, no. 4: 227-231.

Rogoff, B. 1993. Guided participation in guided activity by toddlers and caregivers. Chicago, IL: University of Chicago Press.

Siegel, T. E. 1982. The relationship between parental distancing strategies and the child's cognitive behavior. In Families as learning environments for children, ed. L. Laosa and I. Siegel. New York: Plenum.

Siegel, T. E. 1993. Educating the young thinker: A distancing model of preschool education. In Approaches to early childhood education, ed. J. Roopnarine and J. Johnson. New York: Macmillan.

Smith, W., and D. Dickinson. 1994. Describing oral language opportunities and environments in Head Start and other preschool classrooms. Early Childhood Research Quarterly 9: 345-366.

Tizard, B., M. Hughes, G. Pinkerton, and H. Carmichael. 1982. Adults' cognitive demands at home and at nursery school. Journal of Child Psychological Psychiatry 23, no. 2: 105-116.

Wertsch, J., and C. Toma. 1995. Discourse and learning in the classroom: A sociocultural approach. In Constructivism in education, ed. L. Steffe and J. Gale. Hillsdale, NJ: Lawrence Erlbaum.

Westgate, D., and M. Hughes. 1997. Identifying 'quality' in classroom talk: An enduring research task. Language and Education 11, no. 2: 125-139. 
Wilcox Herzog, A., and S. Kontos. 1998. The nature of teacher talk in early childhood classrooms and its relationship to children's play with objects and peers. Journal of Genetic Psychology 159, no. 1: 30-44.

Wolcott, H. 1988. Writing up qualitative research. Newbury Park, CA: Sage Publications.

Wood, H., and D. Wood. 1983. Questioning the preschool child. Educational Review 35, no. 2: 149-162.

Woodward, C., G. Haskins, G. Schaefer, and L. Smolen. 2004. Let's talk. Young Children 59, no. 4: 92-95.

Appendix 1. Coding of a language event during small group (video no. 1).

T: But you don't want to put too much water on it 'cause then it won't stick. You have to get just the right amount. Gives direction to child

C. OK

T: Rashid are you ready? Invites child to participate

C. Yes

T. Alright. I'll have to get you a small.... What you're gonna have to do is put your name on the bottom. Gives direction to child

T. Any of those colors or you can use some of all of them. Child has choice of color You just need small pieces. And you'll need a pair of scissors. Go get those pair of scissors over there. Tells child to get materials; child has access to materials

$\mathrm{T}$. See one side of this paper is shiny and you are going to put water on it. Be sure you put water on the shiny side. Yep that's it. The other side doesn't have any glue on it. The shiny side has got glue on it. Affirms child's actions and gives directions (Summary of event: Who controls conversation: Teacher; Kind of language: predominantly statements; Cognitive demand: Low; Function of language: Manage instruction)

\section{Appendix 2. Small-group activity session descriptions.}

\section{Mr. Max (Toddler classroom, two-year-old children)}

Activity No. 1 (designing sculptures): During this activity Mr. Max had prepared popsicle sticks, glue, a paintbrush and a tray for each child. Children were given the task of creating sculptures and designs using their popsicle sticks. Mr. Max models how to create a sculpture or design using the popsicle sticks. He also shows children examples of sculptures as well.

Activity No. 2 (creating pictures using wax pencils): children were given construction paper and wax pencils and were instructed to create a picture or design of their choice. As the children create their pictures, Mr. Max draws along with them engaging children in conversations about their pictures. Children in the class rotated freely within this small-group activity.

Activity No. 3 (making Mother Day's cards): Mr. Max gives children crayons and construction paper to create Mother's Day cards. When introducing the activity Mr. Max tells the children they will be making cards for their mommies and could use any color they would like. One of Mr. Max's goals during this activity was to allow all the children in the classroom to have an opportunity to create a Mother's Day card. As a result, he directed and controlled the transitions between children more evidently than in the other small-group sessions.

Activity No. 4 (multiple activities): This was unique to the other small-group sessions. This smallgroup session involved multiple activities in which Mr. Max rotated among the children to ask probing questions and to show interest as they engaged in the activities. The first activity consisted of magnetic animals in which children could mix and match animal parts. The second activity included balance scales and insects in which the children weighed the insects. The last activity required children to match pegs with the sculptured shapes. Children were allowed to move freely from one activity to the next. 


\section{Mrs. Mollie (Preschool classroom, three-year-old children)}

Activity No. 1 (decorating flower vases): This requires the children to follow multiple directions and use a variety of materials; however, the outcome is child-oriented and creative. Children choose different colors and shapes of paper to cut and stick to their yogurt container to make a flower vase for the spring flowers. The paper has a shiny side with glue on it and children use a paintbrush to put water on the shiny side to set and activate the glue. The skills of following directions and fine motor coordination are encouraged.

Activity No. 2 (what hatches from an egg): This is one of the most didactic and content-oriented activities observed; it is a follow up to a story read at circle time about animals hatching from eggs. Mrs. Mollie emphasizes the size of eggs - small, medium and large, amounts of playdough - a lot or a little, and the idea that many different kinds of animals hatch from eggs. This activity is done in three parts: first the children play freely with the playdough, second they open different-sized eggs to see what hatches out, and third they make their own playdough eggs.

Activity No. 3 (planting grass seed): In this case, children are putting earth into a milk carton and sprinkling grass seeds, then watering the seeds. There is a specific order to the process and the amounts of earth, seed and water require control. There is little creativity in this process and all products appear similar on the windowsill. Also, an independent activity, bead stringing, is occurring at the other end of the table and these children need Miss Molly's help and attention on several occasions. The objectives of the activity are less explicit with conversation related to what seeds need to grow.

Activity No. 4 (making a snack together): This is a "cooking" activity; children are making "ants on a log" with celery and peanut butter. This is an activity children have done in the past so not much direction is required. Children have a bowl with peanut butter, a popsicle stick to spread it and small pieces of celery; they eat the snack (and both the celery and the peanut butter) as they talk and continue making their snack. Mrs. Mollie reinforces concepts of healthy snacks, strong teeth and characteristics of vegetables. She asks children one-toone correspondence questions during the lesson as well as graphing the number of children who like/dislike the snack. 